Research Article

\title{
Knowledge and Attitude towards Infection Prevention at a Newly Established Hospital
}

\author{
Haya-Ul-Mujtaba ${ }^{1}$, Nida Anwar²*, Naveena Fatima ${ }^{1}$, Samina Mukry³, Aisha Jamal², Qurat-Ul-Ain Rizvi², \\ Tahir Sultan Shamsi ${ }^{2}$
}

${ }^{\prime}$ Department of Research and Development, National Institute of Blood Disease \& Bone Marrow Transplantation, Karachi, Pakistan.

${ }^{2}$ Department of Hematology, National Institute of Blood Disease \& Bone Marrow Transplantation, Karachi, Pakistan.

${ }^{3}$ Department of Infection Control and Prevention, National Institute of Blood Disease \& Bone Marrow Transplantation, Karachi, Pakistan.

\begin{abstract}
Objective: Health care associated infections are those infections that patients acquire in hospitals during their treatment and health care workers are important source for it. The study was designed to evaluate the knowledge and attitude of Health care workers towards infection control.

Materials \& Methods: A cross sectional study conducted from December 2019 to February 2020 at NIBD \& BMT. Approval was taken from NIBD Research Committee. A pre-designed questionnaire was given to staff that had given informed consent. The questionnaire was composed of two parts. The first part comprised of sociodemographic information and the second part comprising 37 questions of knowledge and 11 question of attitude. Data was analyzed by SPSS version 23. Frequencies and percentages were calculated for categorical variables and mean for quantitative data. Chi-square test was used for association with level of significance as P-value $<0.05$.
\end{abstract}

Results: A total of 82 health care professionals were interviewed. Out of which $49(60 \%)$ were male. The mean age of participants was 28.87 \pm 6.4 years. Majority of staff had graduate or above graduate education 40(49\%). The overall mean knowledge score was found below average with mean of $18.3 \pm 12.3$. The mean knowledge scores between age groups $(\mathrm{p}=0.786)$, gender $(\mathrm{p}=0.760)$ and department $(\mathrm{p}=0.360)$ were not found significant. Knowledge score was significantly different among educations level $(\mathrm{p}=<0.001)$. $71 \%$ were found to have good attitude. Educational status was associated with attitude $(\mathrm{p}<0.001)$.

Conclusion: Our findings revealed below average knowledge however, attitude was found satisfactory. It is the need of time to organize training and educational sessions in order to minimize the rate of infection for the betterment of health care professionals and patients.

Keywords: Healthcare associated infection, Infection control, Knowledge and practices, Attitude towards infection control, Healthcare workers, Pakistan.

\section{INTRODUCTION}

Health Care Associated Infection (HCAI) is one of the major dilemma encountered by developed and under developed countries. It is one of the important cause of increased morbidity and mortality along with great burden on hospital expenditures [1]. The term HCAIs denotes the infections not present initially but acquired by patients during treatment or other health care facilities at the hospital. The average rate of occurrence of HCAIs in developed countries is $15 \%$ however in developing countries it is reported to be $37 \%$ [2]. In USA, death rate due to HCAIs has been reported to be around 40,000 to 80,000 per annum increasing the hospital expenses to about 4.5 billion US Dollars (USD) [3]. In a European study, the occurrence rate of hospital acquired respiratory infection was $7.59 \%$ that develops during 48 hours or more after hospitalization or within 30 days after receiving health care services [4]. While in Southeast Asia the occurrence rate of HCAIs was 9.0\% [5]. A study in Qatar accounted the rate of HCAIs to be $5-10 \%$ in admitted patents i.e. out of every 20

*Address correspondence to this author at the Department of Hematology, National Institute of Blood Disease \& Bone Marrow Transplantation, Karachi, Pakistan. Email: drnidairfan@yahoo.com patients 1 patient had developed HCAIs [1]

Pakistan being a resource constraint under developed region is encountering dual burden of communicable and non-communicable diseases which increases the infectious disease rate as high as $40 \%$ in comparison with the developed countries [6]. A study from Hyderabad, reported the overall rate of HCAIs of about $29.13 \%$ including $39.1 \%$ urinary tract infections, $30.15 \%$ respiratory tract infections, $23.7 \%$ blood stream infections and other $7.1 \%$ were skin, soft tissues, wounds and gastro intestinal infections [7]. The risk of infection is not substantially restricted to patients only but, the workers directly or indirectly involved in patient care are also at risk of acquiring infection [1].

Poor compliance with hand hygiene is considered as the most important source to acquire infection [8]. Infection control measures were initially focused at regional level but now-a-days HCAIs prevention is discussed worldwide [9]. Knowledge and attitude towards the use of personal protective equipment (PPE) and hand hygiene vary among the staff which leads to varying risk of infection acquisition. Health 
care workers (HCWs) are main source of harboring and spreading infections due to compliance issues of proper hand washing protocols and use of PPEs. Thus, the international guidelines for hand washing are effective way to minimize the incidence of HCAIs [10]. There is ample literature in this context to prove the significance of hand hygiene and thus if put into practice can limit the risk of transmission of infection at health care organizations [11].

Our study was designed to evaluate the knowledge and attitude among health professionals towards the basic infection control measures at our newly developed hospital in order to formulate policies and raise awareness for infection prévention among the staff to reduce HCAIs in future.

\section{MATERIALS AND METHODS}

The study was conducted as a cross-sectional study at National Institute of Blood Disease \& Bone Marrow Transplantation (NIBD \& BMT), PECHS Karachi, Pakistan, established in February 2018. Healthcare staffs at our hospital that are directly or indirectly part of patient care were given a questionnaire to evaluate knowledge and attitude towards infection control. For housekeeping department, maintenance, canteen department and staff who were not comfortable and finding difficulty, a clinical research associate interviewed them in a simple language to get the accurate response. However, questionnaire was distributed to doctors, pharmacist, nurses and other healthcare team who were comfortable to fill the questionnaire by their self. Approval was taken from NIBD Research Committee and the study adhered to declaration of Helsinki. Data was collected during the time frame of 03 months, from December 2019 to February 2020. Informed consent was taken prior the enrollment of participants in the study. A questionnaire was created by the infection control team and research team of our hospital. The questionnaire was composed of two parts. The first part comprised of 10 demographics questions including name, age, gender, education, department, religion and marital status, duty hours, employment duration and experience. The second part comprised of questions to evaluate knowledge and attitude. Knowledge was assessed by 37 closed ended questions in which 17 questions were given with the yes and no options and rest of the questions were given with the one correct and up to 4 incorrect answers. For every correct answer, a score of 01 and for incorrect answer, 0 score was given. Knowledge was graded according to the scores achieved; ranged from 0 to 37 in which excellent knowledge was considered for score $>35$, good knowledge 29-34, average knowledge 20-28 and below average knowledge was $<20$. Attitude was assessed by 11 questions consisting of yes and no option. Frequency and percentages were calculated to observe the good and negligible attitude. Participants who were following $70-100 \%$ infection control practices were considered as good attitude and who were following $<70 \%$ infection control practices, they needed improvement in attitude towards infection control practices.

Data was analyzed by Statistical Package for Social Science (SPSS) version 23. Frequencies and percentages were calculated for categorical variables. Mean and standard deviation was calculated for quantitative data. The chi-square test was applied to observe the association of attitude with respect to department, age, gender and education. Independent t-test for two groups and ANOVA for more than 2 groups were applied to observe the mean differences in knowledge scores of stratified groups. In ANOVA, LSD was used for post hoc analysis. Statistical significance was defined for $\mathrm{P}$-value $<0.05$.

\section{RESULTS}

A total of 82 health care professionals were interviewed. Out of which, $49(60 \%)$ were male and $33(42 \%)$ were female. The mean age of participants was $28.87 \pm 6.4$ years. The mean working experience was $5.7 \pm 5.84$ years and mean duration of employment at the institute was $1.1 \pm 0.72$ years. The mean duty hours were $8.88 \pm 1.92$ hours. Majority of staff had graduate or above graduate education $40(49 \%)$. The demographic information of study participants is depicted in Table $\mathbf{1}$.

Table 1. Characteristics of Participants.

\begin{tabular}{|l|l|c|c|}
\hline \multicolumn{2}{|l|}{ Variables } & Frequency & Percentage \\
\hline Gender, Male & Administration & 6 & 60 \\
\hline Departments & Fyy & 2 & 7.3 \\
\hline \multirow{5}{*}{} & Food processing & 2.4 \\
\cline { 2 - 4 } & Clinical services & 13 & 15.9 \\
\cline { 2 - 4 } & House keeping & 10 & 12.2 \\
\cline { 2 - 4 } & Infection Control & 1 & 1.2 \\
\cline { 2 - 4 } & Laboratory & 4 & 4.9 \\
\cline { 2 - 4 } & Nursing & 31 & 37.8 \\
\cline { 2 - 4 } & Pharmacy & 10 & 12.2 \\
\cline { 2 - 4 } & Reception & 3 & 3.7 \\
\cline { 2 - 4 } & Research & 2 & 2.4 \\
\hline Education & Post-graduation & 5 & 6 \\
\hline \multirow{5}{*}{} & Graduate & 35 & 43 \\
\cline { 2 - 4 } & Intermediate & 15 & 18 \\
& (High School) & & \\
\cline { 2 - 4 } & Matriculation & 14 & 17 \\
\cline { 2 - 4 } & Illiterate & 13 & 16 \\
\hline Marital Status & Married & 46 & 56.1 \\
\cline { 2 - 4 } & Single & 36 & 43.9 \\
\hline Religion & Islam & 50 & 61.0 \\
\hline \multirow{5}{*}{} & Christian & 32 & 39.0 \\
\hline
\end{tabular}


The overall mean knowledge score was found below average with mean of $18.3 \pm 12.3$ and $71 \%$ were found to have good attitude. The attitude and knowledge response is presented in
Table 2, it showed that the excellent mean knowledge score was observed in post graduate group and below average score was seen in $<25$ age group.

Table 2. The Attitude and Knowledge of Participants Regarding Infection Control.

\begin{tabular}{|l|c|c|}
\hline Survey Items & Frequency & \% \\
\hline Do you use standard precautions? & 60 & 73.2 \\
\hline Do you use PPE? & 60 & 73.2 \\
\hline Do you wash hand regularly? & 82 & 100 \\
\hline Do you wash hands after removing gloves? & 60 & 73.2 \\
\hline Do you wash hands after patient care events? & 60 & 73.2 \\
\hline Do you cough and sneeze into your elbow area? & 60 & 73.2 \\
\hline Do you wash inter digital spaces? & 25 & 30.5 \\
\hline Do you use alcohol base hand gel when needed? & 62 & 100 \\
\hline Do you dispose of sharps immediately after use? & 60 & 73.2 \\
\hline Do you covers cuts and wounds before performing your duties? & 60 & 73.2 \\
\hline Do you clean contaminated patient care equipments? & 73.2 \\
\hline
\end{tabular}

The mean scores of knowledge and their association with stratified groups is presented in Table 3 . The mean knowledge scores between age groups $(\mathrm{p}=0.786)$, gender $(\mathrm{p}=0.760)$ and department $(\mathrm{p}=0.360)$ were not found significant (Table 3$)$.

Table 3. Association of Knowledge Scores with Study Groups.

\begin{tabular}{|c|c|c|}
\hline \multicolumn{2}{|c|}{ Mean Knowledge Score } & p value \\
\hline Variables & 17.75 & 0.786 \\
\hline$\leq 25$ & 18.57 & \\
\hline$>25$ & 18.60 & 0.760 \\
\hline Gender & 17.80 & \\
\hline Male & & \\
\hline Female & 19.0 & 0.360 \\
\hline Departments & 16.10 & \\
\hline Clinical & & \\
\hline Non clinical &
\end{tabular}

Knowledge score was significantly different among educations level $(\mathrm{p}=<0.001)$. In post hoc analysis, significant difference in mean knowledge score was observed in post-graduation group with graduation, intermediate, and matriculation and mean difference between matriculation and illiterate was also found significant as depicted in Table 4.

Table 4. Association of Knowledge Scores with Education Level by ANOVA, Post Hoc Analysis.

\begin{tabular}{|c|c|c|c|c|}
\hline \multicolumn{2}{|l|}{ Education } & \multirow{3}{*}{\begin{tabular}{|l} 
p value \\
0.407 \\
\end{tabular}} & \multicolumn{2}{|c|}{ 95\% Confidence Interval } \\
\hline & & & \multirow{2}{*}{$\begin{array}{c}\text { Lower Bound } \\
-4.21\end{array}$} & \multirow{2}{*}{$\begin{array}{c}\text { Upper Bound } \\
10.26 \\
\end{array}$} \\
\hline Graduate & Intermediate & & & \\
\hline & Matriculation & 0.216 & -12.08 & 2.78 \\
\hline & Illiterate & 0.21 & -2.57 & 11.55 \\
\hline & Post-graduation & 0.003 & -28.05 & -6.18 \\
\hline \multirow[t]{3}{*}{ Intermediate } & Matriculation & 0.087 & -16.49 & 1.13 \\
\hline & Illiterate & 0.734 & -7.04 & 9.96 \\
\hline & Post-graduation & 0.001 & -32.06 & -8.22 \\
\hline \multirow[t]{2}{*}{ Matriculation } & Illiterate & 0.039 & 0.47 & 17.81 \\
\hline & Post-graduation & 0.043 & -24.5 & -0.42 \\
\hline Post-graduation & Illiterate & 0.000 & 9.79 & 33.41 \\
\hline
\end{tabular}


The attitude of staff among stratified groups is presented in education category $(\mathrm{p}<0.001)$.

Table $\mathbf{5}$ in which significant difference was observed in

Table 5. Association of an Attitude towards the Infection Control with Study Groups.

\begin{tabular}{|c|c|c|c|}
\hline Variables & $\begin{array}{c}\text { Good Attitude } \\
\mathbf{n}(\%)\end{array}$ & $\begin{array}{c}\text { Needs Improvement in Attitude Practice } \\
\mathbf{n}(\%)\end{array}$ & p value \\
\hline \multicolumn{4}{|l|}{ Age (in years) } \\
\hline$\leq 25$ & $16(66.7)$ & $08(33.3)$ & \multirow{2}{*}{0.603} \\
\hline$>25$ & $42(72.4)$ & $16(27.6)$ & \\
\hline \multicolumn{4}{|l|}{ Gender } \\
\hline Male & $33(67.3)$ & $16(32.7)$ & \multirow{2}{*}{0.412} \\
\hline Female & $25(75.8)$ & $8(24.2)$ & \\
\hline \multicolumn{4}{|l|}{ Departments } \\
\hline Clinical & $45(73.8)$ & $16(26.2)$ & \multirow{2}{*}{0.303} \\
\hline Non clinical & $13(61.9)$ & $08(38.1)$ & \\
\hline \multicolumn{4}{|l|}{ Education } \\
\hline Matriculation & $03(23.1)$ & $10(76.9)$ & \multirow{5}{*}{$<0.001$} \\
\hline Intermediate & $10(71.4)$ & $04(28.6)$ & \\
\hline Graduation & $35(100)$ & $0(0)$ & \\
\hline Post Graduation & $02(40)$ & $03(60)$ & \\
\hline Illiterate & $08(53.8)$ & $07(46.7)$ & \\
\hline
\end{tabular}

\section{DISCUSSION}

Globally infection prevention is considered as the key challenge for health care organizations. The present study was conducted to evaluate knowledge, practice of HCWs towards infection prevention at our newly established hospital. In our study, the knowledge was found below average among HCWs which is in contrast than an Ethiopian study conducted in northwest Ethiopia reported to have knowledge rate of $84.7 \%$ [12]. In 2013, a study conducted at India, the general infection control practices and their data revealed only $2 \%$ of the nurses as having excellent knowledge, $24 \%$ having good knowledge, $63 \%$ having average knowledge, and $11 \%$ with below-average knowledge [13]. In our study, $71 \%$ of the participants had good attitude. In contrast, a study was conducted by Unakal et al. [14] in which they found out that good attitude was observed in $48 \%$ participants while in other study $57 \%$ had good attitude [15]. Another study was conducted by Gezie et al. [16] reported that $76.4 \%$ had favorable attitude towards infection control which is somewhat comparable to our findings.

As we are newly established hospital system so, the difference seen in our study might be because of lack of trained staff, and demographic differences. In our study only $25(30.5 \%)$ of staff had previously taken infection control training session. In contrast Ethiopia reported that $57.3 \%$ of staff was involved in infection control activities [12].

Present study comprised 49(59.8\%) male and 33(42.3\%) female staff. The mean age of participants was 28.87 ( $\mathrm{SD} \pm$
6.4) years. From northwest Ethiopia, a study reported a total of 150 health care professionals being interviewed in which $93(62 \%)$ were male. More than half of them $82(54.66 \%)$ were in age range between 26 and 30 years while the mean age was calculated as $25.25(\mathrm{SD} \pm 4.5)$ and majority i.e. $92.66 \%$ were Christians [12]. The mean working experience was $5.7(\mathrm{SD} \pm$ 5.84) years and mean working experience at our institute was $1.1(\mathrm{SD} \pm 0.72)$ year. The mean duty hours was $8.88(\mathrm{SD} \pm$ 1.92) hours.

Our findings revealed that education has significant impact on staff knowledge. HCWs with higher educational level attained more knowledge and attitude scores as compared those having lower educational level. In a study level of education and work experience were significantly associated with safe-infection prevention attitude [15]. A study from Ethiopia also reported as $47 \%$ of the participants being diploma holders and $55.3 \%$ of $\mathrm{HCW}$ as registered nurses [12]. This difference might be result of healthcare workers with higher educational having better essential information [17, 18]. Mean knowledge score was calculated as 18.3 according to our scoring system. However a study from Pakistan revealed the mean knowledge score as (mean score 2) for house officers and junior professionals; while senior professional were found to have a lower mean knowledge score (mean score 1.8) [19]. A study from Rawalpindi revealed that out of 300 workers $281(94 \%)$ were having good knowledge about HCAIs while 143(47\%) use PPE during routine practices [7]. The percentage was lesser than the study conducted in Italy in which only $57 \%$ changed gloves [20]. 


\section{CONCLUSION}

The study was designed to assess the knowledge and attitude of health care professionals regarding infection control at newly established hospital system. In the light of our findings, there is a need to improve the knowledge of healthcare employees by regular educational programs, standard and transmission-based precautions and ward-based hands on teaching practices of care bundles which would help to minimise HCAIs not only for the betterment and safety of patients but also the health care staff.

\section{LIST OF ABBREVIATIONS}

$\begin{array}{ll}\text { HCAI } & \text { Health Care Associated Infection. } \\ \text { PPE } & \text { Personal Protective Equipment. } \\ \text { HCW } & \text { Health Care Worker. } \\ \text { SPSS } & \text { Statistical Package for Social Science. }\end{array}$

AUTHOR'S CONTRIBUTION

Haya-Ul-Mujtaba, Nida Anwar, Naveena Fatima, Samina Mukry, Aisha Jamal, Qurat-Ul-Ain Rizvi, Tahir Sultan Shamsi had substantial contributions to the conception or design of the study, data collection, analysis and interpretation, and in manuscript writing. All authors did the revision of manuscript critically and approved the final version. All authors are able to take public responsibility for the work and are agreed to be accountable for all aspects of the work in ensuring that questions related to the accuracy or integrity of any part of the work are appropriately investigated and resolved.

\section{CONFLICT OF INTEREST}

Declared none.

\section{ACKNOWLEDGEMENTS}

We acknowledge our staff for their cooperation and assistance throughout the study period.

\section{REFERENCES}

[1] Ibrahim AA, Elshafie SS. Knowledge, awareness, and attitude regarding infection prevention and control among medical students: A call for educational intervention. Adv Med Educ Pract 2016; 7: 505. DOI: 10.2147/AMEP.S109830

[2] World Health Organization \& WHO Patient Safety. WHO Guidelines on Hand Hygiene in Health Care. 2009; pp. 1-227. Available at: https://www.who.int/publications/i/item/9789241597906.

[3] Bedoya G, Dolinger A, Rogo K, et al. Observations of infection prevention and control practices in primary health care, Kenya. Bull World Health Organ 2017; 95(7): 5035-16. DOI: 10.2471/BLT.16.179499

[4 Haque M, Sartelli M, McKimm J, Bakar MA. Health care-associated infections-an overview. Infect Drug Resist 2018; 11:
2321-33. DOI: $10.2147 /$ IDR.S177247

[5] Ling ML, Apisarnthanarak A, Madriaga G. The burden of healthcare-associated infections in Southeast Asia: A systematic literature review and meta-analysis. Clin Infect Dis 2015; 60(11): 1690-9. DOI: 10.1093/cid/civ095

[6] Anwar M, Majeed A, Saleem RM, Manzoor F, Sharif S. Assessment of infection control practices in teaching hospitals of Quetta. J Pak Med Assoc 2016; 66(8): 947-51.

[7] Zaidi N, Javed N, Naz S, Mumtaz A. Gaps in knowledge and practices about health care associated infections among health care workers at a tertiary care hospital. J ISB Med Dent College 2016; 5(2): 84-7.

[8] Lahsaeizadeh S, Jafari H, Askarian M. Healthcare-associated infection in Shiraz, Iran 2004-2005. J Hosp Infect 2008; 69(3): 283-7. DOI: $10.1016 /$ j.jhin.2008.05.006

[9] Yokoe DS, Classen D. Introduction: Improving patient safety through infection control: A new healthcare imperative. Infect Control Hosp Epidemiol 2008; 29(S1): S3-11. DOI: $10.1086 / 591063$

[10] Salem OA. Knowledge and practices of nurses in infection prevention and control within a tertiary care hospital. Ann Med Health Sci Res 2019; 9: 422-5

[11] Mathur P. Hand hygiene: back to the basics of infection control. Indian J Med Res 2011; 134(5): 611. DOI: 10.4103/0971-5916.90985

[12] Desta M, Ayenew T, Sitotaw N, Tegegne N, Dires M, Getie $\mathrm{M}$. Knowledge, practice and associated factors of infection prevention among healthcare workers in Debre Markos referral hospital, Northwest Ethiopia. BMC Health Serv Res 2018; 18(1): 465. DOI: 10.1186/s12913-018-3277-5

[13] Sodhi K, Shrivastava A, Arya M, Kumar M. Knowledge of infection control practices among intensive care nurses in a tertiary care hospital. J Infect Public Health 2013; 6(4): 269-75. DOI: 10.1016/j.jiph.2013.02.004

[14] Unakal CG, Nathaniel A, Keagan B, et al. Assessment of knowledge, attitudes, and practices towards infection prevention among healthcare workers in Trinidad and Tobago. Int J Comm Med Publ Health 2017; 7(4): 2240-7. DOI: 10.18203/2394-6040.ijcmph20172813

[15] Bayleyegn B, Mehari A, Damtie D, Negash M. Knowledge, attitude and practice on hospital-acquired infection prevention and associated factors among healthcare workers at university of Gondar comprehensive specialized hospital, northwest Ethiopia. Inf Drug Resist 2021; 14: 259. DOI: 10.2147/IDR.S290992

[16] Gezie H, Leta E, Admasu F, Gedamu S, Dires A, Goshiye D. Health care workers knowledge, attitude and practice towards hospital acquired infection prevention at Dessie referral hospital. Clin J Nurs Care Pract 2019; 3: 59-63. DOI: 
10.29328/journal.cjncp.1001019

[17] Alice TE, Akhere AD, Ikponwonsa O, Grace E. Knowledge and practice of infection control among health workers in a tertiary hospital in Edo state, Nigeria. Direct Res J Health Pharm 2013; 1(2): 20-7.

[18] Fashafsheh I, Ayed A, Eqtait F, Harazneh L. Knowledge and Practice of Nursing Staff towards Infection Control Measures in the Palestinian Hospitals. J Educ Pract 2015; 6(4): 79-90.
[19] Mohiuddin S, Dawani N. Knowledge, attitude and practice of infection control measures among dental practitioners in public setup of Karachi, Pakistan: Cross-sectional survey. J Dow Uni Health Sci 2015; 9(1): 89-93.

[20] Parmeggiani C, Abbate R, Marinelli P, Angelillo IF. Healthcare workers and health care-associated infections: knowledge, attitudes, and behavior in emergency departments in Italy. BMC Infect Dis 2010; 10(1): 35 DOI: 10.1186/1471-2334-10-35 